\title{
Comportamento Humano e Normas de Conduta em Economia Solidária: Relato de Experiência
}

\author{
Ana Lucia Cortegoso ${ }^{1}$ \\ Universidade Federal de São Carlos \\ Vanessa Camargo Franchini Correa Porto \\ Cunha \& Porto Assessoria de Crédito e Cobrança Ltda.
}

\begin{abstract}
RESUMO - Este texto relata a aplicação de procedimento para promover formulação de regras em empreendimentos solidários a partir do conceito de comportamento (relação entre classes de respostas e de estímulos antecedentes e subseqüentes) por membros de uma cooperativa, como parte de capacitação para trabalho cooperativo. Oito mulheres participaram de oficina na qual foram apresentadas informações sobre importância de regras e conceito de comportamento, indicaram comportamentos desejáveis por parte de membros de um empreendimento solidário, descreveram relações comportamentais, desejáveis e indesejáveis, do ponto de vista do grupo, evidenciando capacidade de identificar aspectos relevantes dessas relações e contingências potencialmente mantenedoras de comportamentos de interesse.
\end{abstract}

Palavras-chave: construção de regras; normas comportamentais; economia solidária.

\section{Human Behavior and Conduct Norms in a Solidarity Based Economy: Experience Report}

\begin{abstract}
This study is about the application of a procedure to promote rules formulation in solidarity based enterprises as from the concept of behavior (relations among reply categories and preceding and subsequent stimuli) by members of a cooperative, as part of their capacity development for cooperative work. Eight women participated in a workshop in which information about rules relevance and behavior concept were presented; they pointed out desirable behaviors by members of a solidarity based enterprise, described desirable and undesirable behavioral relations according to the group's point of view, demonstrating capacity to identify relevant aspects of these relations and potential contingencies to the maintenance of these behaviors.
\end{abstract}

Key words: rules construction; behavioral norms; solidarity based economy.

\section{Construção de Normas de Conduta em Empreendimentos Solidários}

Para a legalização de cooperativas, a forma mais típica de empreendimento na Economia Solidária, segundo Singer (2000), é necessário cumprir um conjunto de exigências, sendo uma delas a apresentação de estatuto devidamente aprovado em assembléia. A elaboração desse tipo de documento constitui uma das atividades de qualquer empreendimento em formação para o qual incubadoras universitárias de empreendimentos solidários costumam oferecer assessoria. Mesmo comprometidas com capacitação permanente dos participantes desse processo, particularmente dos membros dos empreendimentos em formação (Cortegoso, Shimbo, Zanin, Fontes, Fontes \& cols., 2005), e do esforço despendido para garantir esse caráter educativo, de modo que o processo de elaboração do estatuto tenha características de educativo, participativo, democrático, auto-gerido e esclarecedor, para que cada interessado possa decidir por aderir ou não à iniciativa, nem sempre é possível garantir todas essas condições no grau desejável. Freqüentemente, a pressão

1 Endereço: Rua Antonio Fiorentino, 58, Jardim Ricetti, São Carlos, SP, Brasil 13570-020.E-mail: cortego@ power.ufscar.br exercida pela necessidade de cumprir exigência legal como condição para iniciar produção ou prestação de serviços e, conseqüentemente, garantir renda para os participantes, muitas vezes favorece elaboração de estatuto como cumprimento de ritual, sem suficiente reflexão coletiva e estabelecimento de acordos internos, fundamentais para funcionamento do empreendimento de modo compatível com princípios da Economia Solidária. Para os autores, importante desafio no processo de assessoramento dos empreendimentos é administrar adequadamente a necessidade de preparo do grupo para funcionamento adequado, incluindo a definição de regras para tanto, e geração de renda.

A experiência de incubadoras universitárias de cooperativas populares ao assessorar grupos deste tipo, com vistas à formação de empreendimentos solidários, tem indicado uma variação considerável em relação à elaboração de normas de funcionamento interno complementares ao estatuto no âmbito desses empreendimentos, assim como em relação a vários outros aspectos do processo de incubação, como evidenciam Cortegoso, Shimbo, Zanin, Fontes, Mascio e Cherfem (2005) examinando suas condutas ao atender três empreendimentos. Algumas variáveis em relação às quais foram identificadas diferenças na elaboração do regimento são o momento do processo de formação do grupo em que isso ocorre (no começo, com o empreendimento já tendo iniciado suas atividades ou com o empreendimento consolidado...); 
o grau de participação dos membros na elaboração dessas normas; os tipos de aspectos que são incluídos no regimento interno, entre outros.

Ao apresentar o processo de incubação em termos de seus próprios comportamentos, e a partir das experiências de incubação acumuladas, uma dessas incubadoras universitárias propôs, como um de seus comportamentos ao assessorar estes grupos, promover elaboração de normas de funcionamento para o empreendimento de maneira participativa. Em relação a esse comportamento, os autores (Cortegoso, Shimbo, Zanin; Fontes, Fontes \& cols., 2005) enfatizam, entre outros, aspectos relativos ao momento em que é recomendável a ocorrência da elaboração do regimento, sugerindo que a equipe garanta que esse instrumento não seja elaborado precipitadamente, quando há maiores chances de artificialidade e não-correspondência com necessidades e peculiaridades do grupo, nem demasiadamente tarde, quando já pode ter ocorrido um grande desgaste dos responsáveis pela administração do empreendimento com a resolução de conflitos e outros problemas.

Ao indicar o que deve ser levado em consideração para promover a elaboração de normas de conduta pelos grupos assessorados, Cortegoso, Shimbo, Zanin, Fontes; Fontes e cols. (2005) incluem características do grupo, princípios da economia solidária e cooperativismo, legislação em vigor para empreendimentos solidários, informações sobre características, funções e objetivos do estatuto e do regimento interno, conhecimento sobre o papel das regras para controle do comportamento humano e sobre características desejáveis de regras. Como resultados, produtos ou efeitos da atuação da incubadora, no que diz respeito à promoção de elaboração de normas por empreendimentos solidários, os autores indicam propriedades desejáveis dessas normas, destacando que essas devem indicar comportamentos (como relações) esperados (ao invés dos proibidos) dos membros, definidos pelo grupo de acordo com suas necessidades e características, de forma compatível com a legislação cooperativista e pertinente à Economia Solidária, de maneira a minimizar a probabilidade de conflitos e distorções em relação aos princípios cooperativistas, favorecer o controle comportamental tecnológico (Glenn, 1986) e positivo (não-coercitivo, de acordo com Sidman, 1995) dos comportamentos desejáveis, compreensão da função da regra e com especificação de consequiências viáveis e proporcionais à gravidade das condutas desviantes para não cumprimento destas regras, bem como compatíveis com o conhecimento sobre o comportamento humano, particularmente aquele controlado por regras.

Não apenas para atender exigências legais, a definição de normas de conduta no âmbito de empreendimentos solidários tem se mostrado importante, especialmente porque esta forma de organização do trabalho, tendo como perspectiva mudanças em diferentes esferas, incluindo as relações entre pessoas e destas com seu meio, pressupõe práticas muito diversas daquelas que são promovidas pela forma de organização social de ordem capitalista. Visando o bem-estar do indivíduo, ao invés de ganho financeiro, a Economia Solidária privilegia: a cooperação ao invés de competição; a participação de todos nos processos de tomada de decisão, gestão e trabalho, com igualdade nas responsabilidades e direitos, ao invés da hierarquização de tarefas e separação de trabalho intelectual e manual, ou planejamento e execução. A promoção de práticas não freqüentes requer o estabelecimento de referenciais comuns para aqueles que fazem parte do empreendimento, e de quem se espera essas práticas, nem sempre bem compreendidas pelos membros do empreendimento. Em um estudo em que caracterizou a compreensão de membros de uma incubadora de cooperativas sobre o que era cooperação e o que significava cooperar, Franchini (2002) encontrou grande variação nas concepções expressas pelos participantes, mesmo em um contexto que tem esse fenômeno como centralidade.

Kunkel (1991), ao examinar apatia e irresponsabilidade em sistemas sociais, ressalta, como um desafio a ser superado, a alta incidência de descumprimento de normas, fenômeno especialmente relevante quando muitas pessoas fazem isso. $\mathrm{O}$ autor examina condições que ajudam na compreensão de razões pelas quais normas são (ou não) respeitadas, ressaltando que o cumprimento de normas, do ponto de vista psicológico, está relacionado às expectativas de ganhos das ações previstas nas normas. $\mathrm{O}$ autor destaca, ainda, a importância de que sejam consideradas, também, regras pessoais, que estão relacionadas à percepção que o indivíduo tem do mundo em que esta norma está inserida, ao examinar razões pelas quais indivíduos cumprem ou não normas estabelecidas pelo grupo social em que está inserido.

Um outro tipo de condição que pode estar relacionada ao cumprimento de normas por um grupo a elas submetido, particularmente considerando as especificidades relativas a empreendimentos solidários, é a "qualidade" dessas normas, tanto em termos do processo de elaboração de regras (que deve ser participativo e democrático), quanto do ponto de vista do produto gerado por meio desse processo, como referencial para guiar a ação de um conjunto de pessoas com histórias de vida diferentes e, conseqüentemente, percepções diferenciadas sobre o mundo e sobre aspectos significativos desse mundo relacionados às normas. Franchini (2003), ao examinar normas usualmente encontradas em diferentes situações, aponta, como características que podem dificultar cumprimento destas normas: a) predominância de normas proibitivas, ao invés de indicativas de comportamentos desejáveis, b) referência apenas às ações pretendidas, sem especificar o contexto em que devem ser apresentadas e os efeitos que devem decorrer dessas ações, c) formulação por meio de termos e expressões vagas, genéricas ou confusas.

A partir dessas constatações, e buscando construir estratégias para assessorar empreendimentos solidários na formulação de normas de conduta para seus membros, compatíveis com suas características, com princípios da Economia Solidária e com conhecimento disponível sobre comportamento humano, Franchini (2003) propôs e implementou um procedimento de intervenção, que incluía capacitar os membros do grupo assessorado para definir comportamento, na concepção sistematizada por Botomé (1981) a partir de conhecimento produzido no âmbito da Análise do Comportamento, em termos de relações entre aquilo que o organismo faz (classes de respostas), as condições diante das quais deve apresentar a ação de interesse e com os quais deve entrar em contato para apresentá-la (classes de estímulos antecedentes), bem como resultados, produtos e efeitos dessas ações (classes de estímulos subseqüentes - ou conseqüentes). 
No procedimento desenvolvido por Franchini (2003), são propostas atividades para promover formulação tecnicamente adequada de normas como comportamentos, e para favorecer geração de produto que bem represente a compreensão do grupo sobre quais comportamentos são desejáveis para garantir os objetivos do grupo como empreendimento de Economia Solidária. Esse procedimento tem sido utilizado em diferentes situações de assessoria a empreendimentos solidários atendidos por uma incubadora universitária, possibilitando identificar em que medida esse procedimento facilita a construção de normas de conduta potencialmente favorecedoras do alcance desses objetivos. A utilização desse procedimento em processo de capacitação de membros de uma cooperativa constitui uma dessas oportunidades, relatada neste estudo.

\section{Aspectos Metodológicos}

Os dados apresentados, relativos a descrições de comportamentos de interesse para membros de uma cooperativa de limpeza a serem considerados para construir normas internas do empreendimento, do ponto de vista de algumas trabalhadoras de uma cooperativa de limpeza que atuavam em conjunto em uma frente de trabalho de apoio a atividades pedagógicas em uma universidade, realizando manutenção de salas de aulas, guarda e empréstimo de equipamentos áudiovisuais, foram obtidos em uma oficina de capacitação dessas participantes para o trabalho coletivo. A oficina foi moderada pelas pesquisadoras, sendo uma delas professora universitária, coordenadora do projeto de incubação da cooperativa, e a outra, aluna de graduação em Psicologia que desenvolvia pesquisa sobre normas de conduta. A cooperativa tinha, na época do estudo, cinco anos de funcionamento, sendo o grupo participante composto por oito mulheres entre 18 e 35 anos, com ensino fundamental completo, parte delas membros da cooperativa desde sua criação e as outras tendo ingressado quando do início da frente de trabalho, aproximadamente um ano antes da realização da coleta dos dados. A oficina teve a duração total de seis horas, tendo sido realizada em dois períodos de três horas cada, um pela manhã e outro pela tarde de um sábado, com intervalo para almoço, e ocorreu em um pequeno auditório de uma universidade pública onde havia cadeiras estofadas. $\mathrm{O}$ procedimento utilizado, nessa situação, foi adaptado de Franchini (2003) e consistiu de: 1) apresentação da proposta de construção de um código de condutas cooperativas para o grupo, por meio de apresentação oral;2) realização de dinâmica ilustrativa do papel de diferentes regras para a conduta humana, sendo utilizado um jogo infantil (super dominó), uma partida com regras usuais, de natureza inteiramente competitiva e outra partida com regras modificadas para promover cooperação e discussão das decorrências de cada uma das regras para a ação das jogadoras; 3 ) apresentação do conceito de comportamento como relação entre o que o organismo faz e o ambiente em que age, em termos de condições antecedentes e condições subseqüentes, de exemplos de descrição de comportamentos simples, da vida diária e de alguns comportamentos relativos a situações usuais de trabalho coletivo, por meio de exposição oral e de cartelas com as informações principais; 4) descrição de situação-problema hipotética, plausível de ser enfrentada por participantes de empreendimentos solidários (surgimento de compromisso inadiável incompatível com assembléia da cooperativa previamente agendada), 5) solicitação para que as participantes indicassem formas de agir que, nesse tipo de situação, poderiam ser consideradas cooperativas ou não-cooperativas do ponto de vista individual de cada uma delas, 6) descrição comportamental de formas de ação indicadas pelo grupo, coletivamente; 7) apresentação sucessiva de variações possíveis em aspectos da situação-problema inicialmente descrita, em relação a propriedades das classes de estímulos antecedentes e subseqüentes componentes das relações comportamentais indicadas pelas participantes, como, por exemplo, maior ou menor grau de contribuição previsto para o membro em conflito, na reunião do grupo, maior ou menor antecedência com que o compromisso incompatível havia surgido em relação à data e horário da reunião etc, para exame pelas participantes e indicação de novas eventuais relações comportamentais de interesse para o grupo no contexto sob discussão. A estratégia geral de implementação do procedimento previsto foi de interação verbal freqüente entre as moderadoras e as participantes, mesmo no caso das exposições, com participação freqüente destas por meio de formulação de perguntas e apresentação de respostas e comentários, espontaneamente ou por solicitação das moderadoras. Os produtos gerados desse processo, em termos de indicações de comportamentos e aspectos desses comportamentos considerados relevantes pelas participantes para o funcionamento do empreendimento de trabalho coletivo, foram registrados em cartelas de papel com letras de tamanho que pudessem ser lidos pelas participantes sentadas em semicírculo diante das moderadoras, a uma distância de aproximadamente três metros, e afixados na parede frontal, em três colunas identificadas como: 1) diante de... (relativa a classes de estímulos antecedentes), coluna à esquerda; 2) ação (classes de respostas), coluna do meio, e 3 ) resultados, produtos ou efeitos esperados das ações (classes de estímulos subseqüentes), coluna da direita. Todas as participantes do estudo consentiram na utilização dos dados obtidos nessa situação para finalidades acadêmicas, por meio de assinatura de consentimento livre e esclarecido.

\section{Resultados e Discussão: Utilização do Conceito de Comportamento para Produção de Normas de Conduta Adequadas em um Empreendimento Solidário}

São apresentadas, como resultados das indicações das participantes do estudo sobre comportamentos de interesse para seu empreendimento solidário, descrições de relações comportamentais apontadas como desejáveis ou indesejáveis por estas participantes. No Quadro 1, na parte superior, pode ser vista a descrição de um comportamento apontado como forma de membros do grupo lidarem com assembléias, considerando relato de uma das participantes sobre o que faria diante de uma situação tal como a apresentada às participantes, envolvendo compromisso pessoal concorrente com assembléia. Na parte inferior do Quadro 1 pode ser vista a descrição proposta pelas participantes para a relação comportamental que melhor corresponderia ao que deveria ser esperado dos membros do empreendimento, com relação 
Quadro 1. Representação esquemática de relações comportamentais correspondentes a formas de membros de empreendimento solidário lidarem com assembléia.

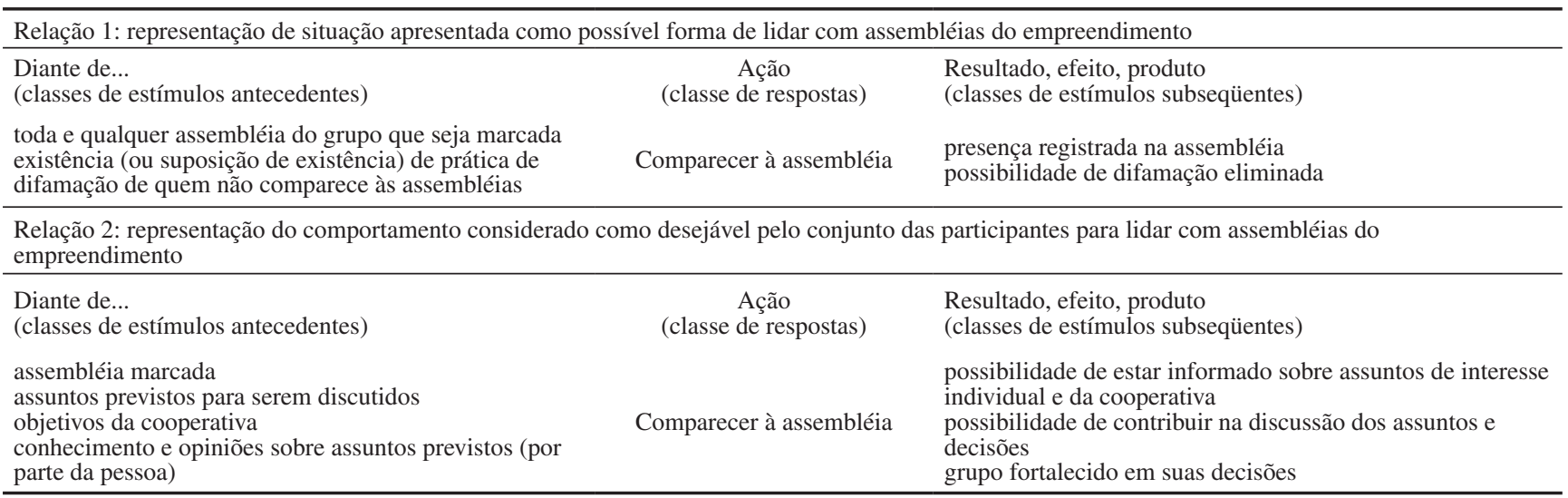

Quadro 2. Classes de comportamentos de membros de um empreendimento solidário consideradas desejáveis, em relação a reuniões do grupo.

\begin{tabular}{ccc}
\hline Diante de... & Ação & Resultado, efeito, produto \\
(classes de estímulos antecedentes) & (classes de respostas) & (classes de estímulos subseqüentes)
\end{tabular}

Reunião do empreendimento agendada;

Surgimento de compromisso no mesmo horário e data, ao qual a pessoa necessita ou deseja comparecer;

Critérios para decisão (por exemplo, gravidade ou urgência das situações a que se referem os compromissos, grau em que as situações dependem da pessoa com compromissos concomitantes, possibilidade de atenuar o prejuízo da ausência em cada um dos compromissos)

Reunião do empreendimento agendada;

Compromisso urgente/ inadiável no mesmo horário da reunião do empreendimento ou surgimento de situações de emergência;

Assuntos previstos para a reunião do empreendimento;

Contribuições definidas ou possíveis para o trabalho do grupo;

Decisão de faltar a uma reunião do grupo;

Decisão de faltar a uma reunião do grupo;

Tempo disponível até o horário da reunião;

Recursos disponíveis para entrar em contato com o grupo;

Decisão de faltar a uma reunião do grupo;

Tempo disponível até o horário da reunião;

Recursos disponíveis para entrar em contato com o grupo;

Assuntos previstos para a reunião;

Contribuições para o trabalho do grupo por parte da pessoa que vai faltar;

Decisões tomadas democraticamente, de acordo com os procedimentos estabelecidos no grupo, em reuniões, estando a pessoa presente ou ausente no processo de decisão

Ausência a uma reunião do grupo;

Fontes de informações sobre a reunião disponíveis;

Recursos para acesso às fontes disponíveis;

Decisão sobre em qual compromisso comparecer tomada de acordo com base nos vários critérios, combinados, de modo que

DECIDIR EM QUAL COMPROMISSO COMPARECER

FALTAR A UMA REUNIÃO DO GRUPO

AVISAR, O

MAIS RÁPIDO

POSSÍVEL, SOBRE

IMPOSSIBILIDADE

DE IR À REUNIÃO

ENVIAR

CONTRIBUIÇÕES

(PRODUTOS,

IDÉIAS,

INFORMAÇÕES)

PARA O GRUPO

Impossibilidade de interferir/participar de decisões do grupo sobre assuntos de interesse comum;

Grupo privado das contribuições específicas da pessoa;

Número menor de pessoas tomando decisões de interesse para o grupo;

Pessoa que falta desinformada sobre ocorrências na reunião;

Outras necessidades da pessoa ou de pessoas fora do grupo atendidas;

Grupo informado, com maior antecedência possível, sobre a ausência;Possibilidade de o grupo minimizar problemas decorrentes da ausência da pessoa;

Redução de probabilidade de especulações e preocupações por parte do grupo, e de ocorrência de atrasos no trabalho do grupo;

Atenuados os prejuízos, para o grupo, da ausência da pessoa na reunião;

Maior probabilidade de serem considerados aspectos diversos e relevantes sobre os assuntos de interesse do grupo a serem tratados na reunião, em processos de tomada de decisão;

\section{ACATAR AS \\ DECISÕES \\ TOMADAS}

INFORMAR-

SE SOBRE OS

RESULTADOS DA REUNIÃO A QUE

ESTEVE AUSENTE
Grupo fortalecido e coeso

Acesso a informações sobre tarefas e decisões tomadas; Conhecimento da próxima pauta ou de discussões pendentes; Maior probabilidade de cumprimento das tarefas determinadas na reunião e de participação nas atividades que necessitarem de apoio. 
a comparecimento a assembléias, em oposição à descrição apresentada na parte superior deste quadro.

De acordo com ponto de vista de sete das oito participantes, que reconheceram a importância de que membros do empreendimento solidário compareçam às assembléias, o comportamento descrito na parte superior do Quadro 1 não corresponderia a uma relação comportamental desejável, uma vez que o comparecimento à assembléia, nessa condição, não estaria controlado pelas razões pelas quais membros de empreendimentos solidários devem participar de atividades de decisão coletiva.

A relação comportamental indicada no Quadro 1 evidencia o comportamento previsto pela regra e indica a contingência que, aparentemente, mantém este comportamento ocorrendo, com controle de natureza essencialmente coercitiva. Comparecer à assembléia como forma de evitar ser alvo de difamação por parte de outros componentes do grupo é um comportamento de esquiva, sujeito a todas as decorrências desse tipo de controle, amplamente demonstradas por meio de estudos experimentais e sintetizadas de forma contundente por Sidman (1995), sendo a dificuldade de manutenção do comportamento na ausência das conseqüências aversivas (difamação ou ameaça de difamação) envolvidas uma delas.

No caso do comportamento representado - e contingência sugerida - na parte inferior do Quadro 1, comparecer à reunião é um comportamento que deveria estar sob controle dos benefícios produzidos - para o próprio indivíduo como co-responsável pelo empreendimento em igualdade de condições com todos os outros e com direitos de participação também iguais, e para o grupo, em função de sua contribuição para o processo decisório - pela resposta de comparecer à reunião. Ou seja, esta sim uma relação comportamental compatível com as características de um empreendimento solidário.

A continuidade do processo de discussão da situaçãoproblema, com sugestões de variação em propriedades das classes de estímulos antecedentes e a partir de classes de estímulos antecedentes geradas por classes de respostas relacionadas à situação-problema, possibilitaram a identificação e descrição de outras relações comportamentais de interesse para o empreendimento, relativas a situações que envolvem compromissos conflitantes, que podem ser examinadas no Quadro 2.

A discussão desenvolvida a partir de uma situaçãoproblema típica dentre as que são enfrentadas por membros de empreendimentos solidários, em que o comparecimento a reuniões deliberativas é condição fundamental para o processo democrático previsto para estes empreendimentos e costuma ser obrigatório (com conseqüências punitivas previstas para sua não-ocorrência) propiciou o aparecimento de variações em aspectos dessa situação-problema, permitindo que as participantes identificassem outras classes de comportamentos relevantes, considerando a construção de normas de conduta pelo empreendimento, como decidir a que compromisso comparecerá. A descrição dessa classe de comportamentos evidencia que a decisão final poderá ser a de não-comparecimento à assembléia do empreendimento, desde que considerados e comparados prejuízos e benefícios correspondentes a comparecimento ou não em cada um dos compromissos. Da decisão de faltar a uma assembléia decorreram, neste caso, outras classes de comportamentos, descritas de acordo com o que as participantes entendiam como compatível com os interesses do empreendimento e, nesse sentido, normas a serem seguidas pelos seus membros.

Os comportamentos indicados no Quadro 2 apresentam graus diferentes de especificidade, e sua descrição coloca em evidência aspectos diversos que sinalizam a necessidade de cuidados ao construir normas, de modo que elas sejam compatíveis com a complexidade e variabilidade ambiental. Desta forma, ao invés de seguir simplesmente a uma única regra, foi possível evidenciar que os membros do empreendimento deverão implementar um processo de tomada de decisão pessoal - com decorrências para si e para o grupo - complexo, e sujeito à influência de diversas variáveis. Por exemplo, o grau de contribuição que o indivíduo que vive o conflito pode ou deve dar para as questões que serão abordadas na reunião, como condição importante para decidir sobre seu comparecimento ou não a ela. Em Los Horcones (2006), comunidade que adotou um sistema de tomada de decisão por consenso, qualquer membro pode optar por não ir a uma reunião deliberativa, tendo como única decorrência que deverá aderir às decisões que porventura sejam feitas nessa reunião.

O exame das formulações apresentadas como resultado da discussão das participantes da oficina permite notar que não foram incluídos, nestas formulações, aspectos relacionados a conseqüências arbitrárias para não-cumprimento das regras, uma vez que o procedimento previa apenas a indicação das relações comportamentais desejáveis. Assim como não foram incluídas, especificamente, consequiências arbitrárias voltadas para a manutenção das condutas desejáveis, ainda que alguns produtos, efeitos ou resultados das respostas indicados nas formulações possam, e de preferência devam apresentar propriedades reforçadoras, em especial se corresponderem a condições estabelecidas, no âmbito do grupo, como de valor para o próprio grupo. A previsão e implementação de tais consequiências, tanto fortalecedoras dos comportamentos desejáveis quanto inibidoras de comportamentos indesejáveis, serão provavelmente necessárias para instalar e manter repertórios apropriados dos membros, constituindo outra dimensão relevante para controle dos comportamentos especificados nas regras.

\section{Conhecimento sobre comportamento humano na construção de normas de conduta}

De acordo com Blake e Davis, citado por Kunkel (1991, p. 227), a definição clássica de norma é "qualquer padrão ou regra que estabelece o que seres humanos devem ou não devem pensar, dizer ou fazer sob certas circunstâncias", e seu papel, segundo este autor, é "guiar atividades das pessoas ligando os comportamentos que a cultura define como 'apropriada' em uma situação específica a várias conseqüências. $\mathrm{O}$ enunciado de Kunkel mais claramente, mas também a definição de Blake e Davis, estabelecem relações importantes entre normas e conceitos desenvolvidos e utilizados no âmbito da Análise do Comportamento. De forma direta e explícita ao conceito de comportamento, como 
relação entre a ação de um organismo (seres humanos, neste caso) e seu ambiente, e de forma implícita ao conceito de contingência ("várias consequiências" a que as ações estão ligadas pela norma).

Uma adequada e completa descrição de comportamentos a serem normatizados no âmbito de um grupo como condição para que sejam alcançados os resultados pretendidos em um empreendimento solidário - ou em qualquer outro tipo de organização - pode ser considerada fundamental para o estabelecimento de normas com maior probabilidade de serem cumpridas - uma vez que especificam os aspectos do ambiente que devem ser considerados, seja como sinalizadores de que um determinado tipo de resposta do organismo é conveniente, adequado ou oportuno aqueles com os quais o organismo deverá entrar em contato para apresentar a resposta ou como resultados, produtos ou efeitos que devem decorrer desta resposta (Botomé, 1981). Pode não ser, contudo, condição suficiente para controlar adequadamente o comportamento daqueles que estão sujeitos à norma, uma vez que muito freqüentemente as decorrências "naturais" das respostas consideradas nas descrições não são suficientes para manter estas respostas ocorrendo. Ou seja, condições subseqüentes podem não apresentar propriedades reforçadoras para indivíduos que estão sujeitos à norma. Isto pode ser particularmente verdadeiro no caso de comportamentos relacionados a resultados, produtos ou efeitos que não são imediatos, ou que não se referem apenas, nem mesmo preponderantemente, ao indivíduo que apresenta estas respostas, como é o caso de situações de trabalho coletivo, típicas dos empreendimentos da Economia Solidária, um campo da atividade humana no qual se espera que o indivíduo se comporte de modo muito diferente daquele que é produzido e fortemente estimulado em uma sociedade que privilegia a competição, valoriza o acúmulo de bens e de vantagens individuais.

No caso de sociedades como a ocidental moderna, e mesmo considerando o contexto da Economia Solidária, em última análise inserida nesta mesma cultura embora buscando constituir frente de resistência e de mudança, a inclusão de conseqüências específicas para a apresentação de comportamentos desejáveis pode ser também fundamental como parte da descrição das classes de estímulos subseqüentes e com uma função clara de conseqüências capazes de manter estes comportamentos. Uma explicitação que pode, ainda, aumentar a probabilidade de que a comunidade que deve providenciar estas conseqüências (o grupo em que o indivíduo está inserido) possa compreender seu papel de forma clara e inequívoca e incluir, entre suas normas, comportamentos relacionados à liberação destas conseqüências, formando aquilo que Kunkel (1991) denomina de estruturas sociais, ou seja, atividades de muitas pessoas conectadas por diversas equivalências, e que pode ser fundamental para garantir o cumprimento das normas estabelecidas, segundo este autor.

Na mesma direção dessas considerações sobre características relevantes de normas de conduta a partir de conhecimento sobre comportamento humano, Todorov, Moreira, Prudêncio e Pereira (2005), ao examinar contingências e metacontingências no Estatuto da Criança e do Ado- lescente - ECA (Brasil, 1990), alertam para importantes lacunas na descrição das contingências contempladas no texto, e apontam decorrências dessas lacunas para a efetiva implementação da lei. Os autores ressaltam que falta de especificação de aspectos relevantes das contingências pode levar a incertezas quanto ao papel de cada um dos agentes que se encontram sob as diretrizes do ECA, assim como, em um grupo auto-gestionário, os membros podem não considerar adequadamente o conhecimento disponível sobre o papel das conseqüências para a manutenção do comportamento humano, colocando em extinção ou mesmo punindo comportamentos desejáveis de seus membros, particularmente aqueles mais recentemente desenvolvidos ou frágeis no repertório comportamental desses indivíduos.

Outro aspecto relativo a características de normas em relação ao qual há conhecimento relacionado ao comportamento humano disponível - e freqüentemente menosprezado - diz respeito à natureza das contingências usualmente descritas por normas, que se referem, em geral, a um conjunto de proibições (comportamentos que não devem ser apresentados) e de sanções previstas para aqueles que descumpram tais proibições, duas condições que podem ser consideradas insatisfatórias, diante do conhecimento disponível sobre o comportamento humano. A primeira delas, relativa ao uso de normas que indicam apenas o que não pode ser feito, sem indicar claramente as alternativas aceitáveis para lidar com as situações a que as normas se referem, podem levar a comportamentos tão ou mais inadequados que aqueles a serem evitados por meio das normas, ou pelo menos deixar desorientados aqueles que estão expostos a elas. A segunda das condições usualmente encontradas em normas formuladas para regular os mais diferentes aspectos da vida em sociedade é o uso evidente e intenso do controle coercitivo como forma preponderante de controle. Sidman (1995), ao sintetizar descobertas resultantes de estudos produzidos em mais de 50 anos de pesquisa com animais e com seres humanos em laboratórios e em situações naturais, relacionadas ao uso de punição, demonstra, de forma contundente, os danos para indivíduos e para a sociedade da produção de repertórios comportamentais de fuga e esquiva como formas privilegiadas dos seres humanos lidarem com seu ambiente - sendo outros homens e seus comportamentos partes fundamentais desse ambiente.

No caso da Economia Solidária, em que práticas cooperativas, processos democráticos de decisão com participação igualitária de todos os membros de empreendimentos solidários, são almejados não apenas nas decisões, mas na implementação destas decisões, a elaboração de normas de conduta nestes padrões (com indicação de proibições e sanções para comportamentos indesejáveis como informações preponderantes nas normas propostas) é algo tão mais surpreendente quanto indesejável. No entanto, experiências de acompanhamento de grupos solidários em processos de elaboração de suas normas internas mostram que isto ocorre e, embora possa ser compreendido pelo fato de que as pessoas que constituem estes empreendimentos fazem parte da sociedade em que práticas coercitivas são estimuladas e mantidas, parece 
fundamental utilizar o conhecimento sobre o comportamento humano para gerar normas de melhor qualidade como ferramenta para a produção de novas práticas culturais, tanto internamente nos empreendimentos solidários quanto, a partir deles, na sociedade em geral.

\section{Eficácia de normas no controle dos comportamentos a que se referem}

Para alcançar seus objetivos, a proposição de normas com indicação de comportamentos (como relações ambiente-organismo) desejáveis do ponto de vista do grupo parece constituir um relevante ponto de partida, embora possa não ser condição suficiente para promovê-los. Ela pode prever (se necessário) conseqüências arbitrárias capazes de promover a instalação de comportamentos novos, preferencialmente por meio de contingências não-coercitivas (reforçamento positivo) ou, no máximo, coercitivas brandas, como oportunidade para cessar comportamentos indesejáveis e instalar outros de maior relevância para o indivíduo e para o grupo, conforme recomenda Sidman (1995) ao reconhecer as dificuldades existentes para implementar apenas contingências positivas em uma cultura que "naturalizou" o controle coercitivo, embora possa não ser condição suficiente para promover os comportamentos definidos como desejáveis, parece constituir um relevante ponto de partida nesta direção. O cumprimento de normas, mesmo com essas características, depende, contudo, de outras condições, que também deverão ser consideradas por quem formula tais normas, e por quem assessora esse processo de formulação, como é o caso das incubadoras universitárias de empreendimentos solidários, sendo apenas parte dessas variáveis conhecidas, assim como é parcial o conhecimento sobre o impacto das variáveis já identificadas como relevantes para cumprimento das normas em diferentes contextos.

Ao examinar condições relacionadas a cumprimento e descumprimento de regras, Kunkel (1991) destacou, como condições relevantes para cumprimento de normas, compatibilidade destas com outras do subgrupo a que cada indivíduo pertence, expectativa de ganhos com as ações previstas pelas normas e estilo individual de atribuição de causalidades, ressaltando que seguir ou não uma regra estabelecida socialmente dependerá, entre outras coisas, das fontes a que o indivíduo atribui a ocorrência de consequiências tais como aquelas que a norma propõe como decorrentes da conduta do indivíduo. O cumprimento ou não de normas dependerá, ainda, do grau em que as contingências previstas pelas normas sejam "confirmadas" no mundo real, ou seja, que as conseqüências estabelecidas pela norma efetivamente ocorram, uma vez apresentados (ou omitidos) os comportamentos correspondentes. Embora, de acordo com Mallot (1988), a grande maioria dos comportamentos humanos seja, em nossa sociedade moderna, mantida por meio de regras (e não por contingências estabelecidas por meio de relações entre nossa conduta e mudanças materiais no mundo), normas que não apresentem tal confirmação tenderão, de um modo geral, a serem simplesmente abandonadas, a menos que sustentadas por um forte controle de natureza cerimo- nial, aquele em que a manutenção dos comportamentos se dá por meio de reforços sociais cujo poder advém do status, da posição ou da autoridade do agente reforçador, podendo não estar relacionados a quaisquer mudanças ambientais que, direta ou indiretamente, beneficiem quem se comporta (Glenn, 1986).

Por tal razão, parece de fundamental importância que as conseqüências indicadas como parte de normas, particularmente as de cunho arbitrário, destinadas especificamente a diminuir a probabilidade de ocorrência de comportamentos indesejáveis sejam viáveis, compatíveis com o grau de gravidade dos comportamentos a serem evitados e com conhecimento disponível sobre comportamento humano, em especial o controlado por regras (Cortegoso, Shimbo, Zanin, Fontes, Fontes \& cols., 2005).

\section{Referências}

Brasil (1990) Lei 8069 de 13/07/1990. Estatuto da Criança e do Adolescente. Diário Oficial da República Federativa do Brasil, Brasília, DF, 16 julho 1990.

Botomé, S. P. (1981). Objetivos de Ensino, necessidades sociais e tecnologia educacional, 1981. Tese de Doutorado, Universidade de São Paulo, São Paulo.

Cortegoso, A. L., Shimbo, I., Zanin, M., Fontes, D. A., Fontes, N., Jesus, V. M. B. De, Uehara, M. S., Mascio, C. C., Costa, A. A. V. Da \& Nardini, T. (2005, novembro). Método de incubação como referencial para atendimento a empreendimentos solidários: a experiência da Incubadora Regional de Cooperativas Populares da UFSCar. Trabalho apresentado na $2^{\text {a }}$. Jornada Universitaria sobre Cooperativismo, Economía Solidaria y Procesos Asociativos, Montevidéo, Uruguai.

Cortegoso, A. L., Shimbo, I., Zanin, M., Fontes, D. A., Mascio, C. C. \& Cherfem, C. O. (2005, novembro). Variáveis que influem no processo de incubação de empreendimentos solidários: um exame de três experiências com base no método de incubação da INCOOP/UFSCar. Trabalho apresentado na $2^{\text {a }}$. Jornada Universitaria sobre Cooperativismo, Economía Solidaria y Procesos Asociativos, Montevidéo, Uruguai.

Franchini, V. de A. C. (2002). Concepção de mediadores de uma incubadora de cooperativas populares sobre cooperação (Relatório processo 23112000151/2001). São Carlos: PróReitoria de Extensão/Universidade Federal de São Carlos.

Franchini, V. de A. C. (2003). Procedimento para elaboração de um código de condutas cooperativo em cooperativas populares de trabalho em incubação. Monografia de graduação, Universidade Federal de São Carlos, São Carlos.

Glenn, S. S. (1986). Metacontingencies in Walden Two. Behavior Analysis and Social Action, 5(1), 2-8.

Kunkel, J. H. (1991) Apathy and irresponsibility in social systems. Em P. A. Lamal (Org.), Behavioral Analysis of societies and cultural practices (pp. 219-240). New York: Hemisphere Publishing Corporation.

Los Horcones (2006). Personocracia. Retirado em 26/02/2006, de www.loshorcones.org.mx/personocracia.html

Mallot, R. W. (1988). Rule-governed behavior and behavioral anthropology. The Behavior Analyst, 11(2), 181-203.

Sidman, M. (1995). Coerção e suas implicações. (M. A Andery \& T. M. Sério, Trads). Campinas: Editorial Psy. (Trabalho original publicado em 1989) 
Singer, P. (2000). Economia solidária: um modo de produção e distribuição. Em P. Singer \& A. R. Souza (Orgs.), A economia solidária no Brasil (pp. 11-28). São Paulo: Contexto.

Todorov, J. C., Moreira, M., Prudêncio, M. R. A. \& Pereira, G. C. C. (2005). Um estudo de contingências e metacontingências no estatuto da criança e do adolescente Em J. C. Todorov, R. C. E.
Martone, M. B. \& M. B. Moreira (Org.), Metacontingências: comportamento, cultura e sociedade (pp. 45-53). Santo André: ESETec.

Recebido em 10.03.2006

Primeira decisão editorial em 10.05.2006

Versão final em 27.07.2006

Aceito em 15.02.2007

\section{ASSINATURA PARA INSTITUIÇÕES}

Assinaturas de Psicologia: Teoria e Pesquisa podem ser solicitadas diretamente à:

Secretaria de Divulgação

Revista Psicologia: Teoria e Pesquisa

Instituto de Psicologia, Universidade de Brasília

70910-900 Brasília, DF, Brasil.

O valor da assinatura anual é R\$130,00. Número avulso para assinantes custa $\mathrm{R} \$ 26,00$ e número antigo R\$20,00. Número avulso para não assinantes custa $\mathrm{R} \$ 48,00$. Valores sujeitos a atualização. 